\title{
Fee-for-service payment - an evil practice that must be stamped out?
}

\section{Naoki Ikegami*}

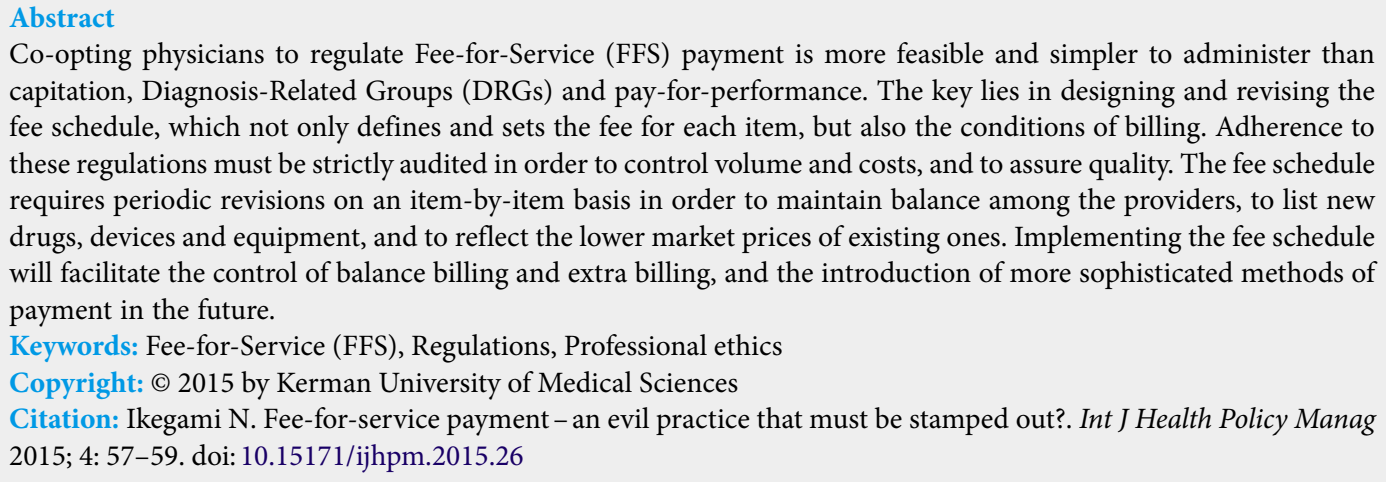

Co-opting physicians to regulate Fee-for-Service (FFS) payment is more feasible and simpler to administer than capitation, Diagnosis-Related Groups (DRGs) and pay-for-performance. The key lies in designing and revising the fee schedule, which not only defines and sets the fee for each item, but also the conditions of billing. Adherence to these regulations must be strictly audited in order to control volume and costs, and to assure quality. The fee schedule requires periodic revisions on an item-by-item basis in order to maintain balance among the providers, to list new drugs, devices and equipment, and to reflect the lower market prices of existing ones. Implementing the fee schedule will facilitate the control of balance billing and extra billing, and the introduction of more sophisticated methods of payment in the future.

Keywords: Fee-for-Service (FFS), Regulations, Professional ethics

Copyright: () 2015 by Kerman University of Medical Sciences

Citation: Ikegami N. Fee-for-service payment - an evil practice that must be stamped out?. Int J Health Policy Manag 2015; 4: 57-59. doi: 10.15171/ijhpm.2015.26

\section{Article History:}

Received: 13 January 2015 Accepted: 5 February 2015 ePublished: 6 February 2015
$\mathrm{T}$ There appears to be a general consensus that Fee-forService (FFS) payment is an evil practice leading to overprovision, inefficiency and uncontrollable health expenditures (1). The assumption is that FFS encourages physicians to deliver more and unnecessary services to maximize their income. However, physicians have historically been paid FFS and it continues to be the dominant method in most countries. Physicians have preferred FFS because they would be compensated for delivering the best care to patients according to their professional standards. Physicians have also claimed that they waive or decrease payment for patients unable to pay by providing charity care with the balance met by charging rich patients.

This professional model has been criticized as being a facade for hiding the self-interest of the physician as an individual and as a group (2). There has been heightened awareness of the need for equity and transparency, and in many countries, the state, and not individual physicians, has assumed the primary responsibility for making appropriate care available to all. However, the same asymmetry of information that exists between the patient and the physician also exists between the government and physicians. Therefore, the government must co-opt physicians in pursuing their goals. They must find a middle ground between what the country can afford to spend on health care, and the extent of services that health professionals believe they should provide, and, equally important, how much their income should be. The former depends on the resources available and on how much the rich and healthy are prepared to pay for the health expenditures of the poor and chronically ill. The latter has never been specified, but a common assumption is that physicians should earn a "comfortable income".

In most high-income countries, governments have been able to agree with physician associations on the "appropriate" levels of services and physicians' incomes. The most notable exception is the United States (U.S), where the task has been mostly left to private health insurance plans and providers. This has resulted in cost escalations, inequity and high administrative costs as each player has tried to game at the expense of others, while its health outcomes remain mediocre compared with other high-income countries. It also allowed some physicians to earn twenty times the income of the average worker (or that of a nurse), and for cardiac surgeons to earn three times or more the income of general practitioners (GPs). Policy-makers in low- and middle-income countries should be aware that most alternative models to FFS payment have been designed to address the problems peculiar to the American healthcare system, based on microeconomic theories that physicians will maximize their utility (3). This point is illustrated by the brief description below of the development of these methods in the U.S and their inherent problems (4).

Health Maintenance Organizations (HMOs) came to be promoted from the late 1960s as a way to combine health insurance with the actual provision of care. The underlying assumption was that providing capitated payment to primary care physicians according to the number enrolled would contain costs by incentivizing them to improve health status. It later developed into numerous complex patterns under the general rubric of "managed care". Therefore, the caveats of capitation could be better understood by looking at the British National Health Service. While in theory GPs are competing for enrolees, in practice, only very few actually change their GPs each year. Moreover, popular practices cannot accept new enrolees once they have reached the maximum allowed per GP. Nor would competition be feasible in rural settings. Capitation also leads to long waiting lists for hospital specialist services because GPs have little incentive to treat time-consuming complicated patients. There is no 
evidence to support the superiority of capitation over other forms of payment (5).

Case-based payment or Diagnosis-Related Groups (DRGs) were introduced in 1984 to replace the unregulated FFS payment to hospitals for inpatient care (payment to physicians has continued to be FFS). DRGs had a one-time effect in containing inpatient care costs but those were offset by increases in outpatient care and nursing home costs. Other countries in Europe introduced DRGs for entirely different reasons: to provide incentives to hospitals by replacing fixed budgets that had caused long waiting lists. Whether the introduction of DRGs had the desired effects is difficult to evaluate because they were part of structural reforms to improve hospital efficiency (6).

Pay-for-Performance (P4P) gives bonus payment for physicians who achieve pre-defined clinical targets. Although in theory $\mathrm{P} 4 \mathrm{P}$ is an ideal payment mechanism, there is at most mixed evidence of their results, and much depends on the context $(7,8)$. Critics also voiced concerns about strict metrics used to evaluate performance. Keeping cholesterol and blood pressure below prescribed targets may be beneficial for population health, but not for all patients. Some "processdriven" $\mathrm{P} 4 \mathrm{P}$ indicators, for example prescribing beta-blockers, are contra-indicated for some patients (9). Theoretically, $\mathrm{P} 4 \mathrm{P}$ indicators could be developed based on risk adjusted outcomes, but physicians are generally uncomfortable and unconvinced with the results of such complicated statistical analysis. Methodologically, all P4P indicators must avoid the "ceiling effect" (providing additional income to nearly all) and the "floor effect" (payment so little as would be disregarded by most).

What is common with the above alternative methods of payment is that they require more complex mechanisms than regulating FFS to ensure they function appropriately. This is to some effect inevitable as they were designed for the highly sophisticated U.S. healthcare system. Capitation payment in primary care may appear attractive, but aside from the caveats described, many countries have difficulty in attracting physicians to general practice. DRGs and P4P require welldesigned patient identification, classification, recording and monitoring systems. In DRGs, measures to mitigate providers from up-coding (coding patients to higher paid groups than is appropriate) must be made. Monitoring under-provision of services is more difficult than overprovision in FFS because, for some patients, bed rest and observation may be the best treatment.

Moreover, there are fundamental and practical problems inherent to the above alternate payment models. The incentives target provider organizations, which in turn must persuade individual physicians to deliver services more efficiently. But physicians have not been trained to take on such responsibilities. To them, their professional code to provide the best care for the patient takes precedence. There are few circumstances in which physicians agree to explicitly ration resources in order to maximize societal benefit, for example the allocation of transplant organs or the triage of patients in an emergency or following a disaster. On the other hand, there is a risk that the organization succeeds too well in persuading physicians to cooperate and thereby maximize profits for both parties.
As a practical problem, FFS will remain the dominant method of payment for privately financed healthcare. In particular, for physicians who have newly opened offices, FFS would be the only feasible option as the transfer of capitation payment from existing ones is difficult. Since physicians in many countries have dual appointments, they have every incentive to direct patients to privately financed facilities (either co-located to a public hospital or stand-alone). Patients who are able to pay can avoid queues, enjoy better amenities and access to perceived high quality care. Thus, as general income levels rise, the share of privately financed services is likely to increase and so will the disparity. Moreover, private payment is not restricted to private facilities: publicly financed facilities may continue to charge patients for services not covered (extrabilling) or to charge more (balance billing), which will defeat the purpose of introducing DRGs or capitation.

I have come to the conclusion that, rather than to regard FFS payment as an evil practice, it would be more practical and preferable to co-opt physicians into developing a fee schedule that defines and sets the fee of each item. It must also define the conditions of payment based on the provider's capacity to appropriately deliver the service and on the patient's clinical needs. Imposing and monitoring adherence to these regulations can not only mitigate inappropriate volume expansion but also assure basic quality standards be met. It should also facilitate the control of extra billing and balance billing by explicitly setting the terms for billing publicly financed services. Moreover, if privately financed facilities could be persuaded to adopt the same classification system, it would decrease their administrative costs and, in the longer term, pave the way for the eventual unification of fees and payment conditions with the publicly financed facilities.

Designing the fee schedule is much more of a political, rather than an economic, process. Elaborate cost studies have little value because the results would only reflect those of the facilities studied and become quickly dated. Political commitment at the highest level, a core team of dedicated bureaucrats to negotiate with stakeholders, design and conduct surveys, and process data, and the establishment of a high level, statutory defined government committee to which renowned physicians would be invited as members are needed. The first task would be to ask specialist groups to set the relative fee of each procedure by comparing with a base. Their results could be bridged by the procedures performed by two or more specialties. In doing so, it is critical to prevent powerful specialties from skewing the values to their advantage, and to ensure that primary care services are given high values. Proactive management of conflict among and within physicians' associations would be needed.

The next task would be to precisely define each item and set the conditions for billing. For example, which physician consultations are "initial", and which ones are "repeat"? The former requires more time than the latter thus justifying a higher fee. Unless there is some specification about the number of days since the last visit, physicians can be tempted to bill all visits as "initial". Simple procedures, such as urine tests, should be specified and included in the consultation fee. Costs could be contained by specifying the extent and frequency of laboratory tests appropriate for a disease and by degree of severity. On the other hand, conditions could be set 
for quality purposes such as higher payment for bed and board if the hospital has a high nurse staffing ratio (on condition that licensure of nurses meets appropriate standards). Compared with process and outcome measures in $\mathrm{P} 4 \mathrm{P}$, they would be easier to measure and audit.

The price for prescription drugs, devices and use of equipment (such as MRI) depends on the international markets where countries can leverage their buying power. For drugs, whether the drug is protected by patent or not is crucial because the industry has maintained that the high costs of launching a new brand drug come from Research and Development ( $\mathrm{R}$ \& D), not from its manufacturing. For devices and use of equipment, whether the patent is active or not is less important because, unlike drugs, improvements are constantly made, so that the price of an old model could be rapidly driven down by competition. Strict conditions of billing similar to that for services must be set in addition to meeting efficacy and safety standards evaluated by clinical trials.

Next, to monitor adherence to the conditions of billing, there must be a process of auditing the claims (bills) sent by providers. This would be of three levels. The first is screening by the administrative staff, which would be facilitated by electronic billing. The second is in depth reviews by physicians, preferably by prestigious clinicians of the same specialty. The third is on site audits of the medical records to cross-check whether the patient had actually met the conditions of billing for the services, drugs and so forth, with penalties for failing to provide documentation. Auditing would be easier for FFS than for other forms of payment because the government has data on the itemized services billed.

Finally, a crucial component in regulating FFS payment is devising the method for periodically revising the fee schedule. This should be made on an item-by-item basis in order to maintain balance among the providers, to list new drugs, devices and equipment, to reflect the lower prices paid by providers of existing ones, and to remedy any unexpected behaviour of providers that has occurred after the previous revision (10). If the imbalance is not addressed, physicians in some specialties would continue to earn more income than others, and exacerbate the existing mal-distribution by attracting a disproportional share of medical school graduates. The market will not redress this imbalance because physicians can induce demand.

Revisions also play a crucial role in containing costs. While the introduction of new technology does drive up costs, competition should drive down the price of existing ones because healthcare providers would try to purchase them at the lowest price. These reductions could be used to mitigate increases in health expenditures due to non-price factors: demographics (population increase and aging) and advances in technology. Should the savings exceed the fiscal space available, then service fees must be reduced. The simplest way is by decreasing the conversion factor but such an across-theboard decrease would unite all providers in opposing such a revision. This is another reason why revisions should be made on an item-by-item basis, which would enable policymakers to divide and rule. By weighing the impact of revising each item by its volume, and then adjusting their cumulative impact on the total expenditures, it is possible to set by a global budget despite the seemingly open-ended FFS payment.

Designing and revising a fee schedule is a daunting task for low- and middle-income countries because the disparity between the norms set in medical textbooks and the resources available is greater than in high-income countries. However, FFS should first be regulated before introducing more sophisticated methods of payment. This editorial has presented a conceptual explanation of how payment has been regulated by the fee schedule in Japan. For further details refer to the publication listed (11).

\section{Ethical issues}

Not applicable.

Competing interests

Author declares that he has no competing interests.

Author's contribution

$\mathrm{NI}$ is the single author of the manuscript.

\section{References}

1. World Health Organization (WHO). Health System Financing. Geneva: WHO; 2010. p. 72-5.

2. Marmor TR, Gordon RW. Commercial pressures on professionalism in American medical care: From Medicare to the Affordable Care Act. J Law Med Ethics 2014; 42: 412-20. doi: 10.1111/jlme. 12164

3. Chinitz D, Rodwin VG. What passes and fails as health policy and management. J Health Polit Policy Law 2014; 39: 1113-26. doi: $10.1215 / 03616878-2813719$

4. Field RI. Health Care Regulations in America. New York: Oxford University Press; 2007.

5. Gosden T, Forland F, Kristiansen I, Sutton M, Leese B, Giuffrida A, et al. Capitation, salary, fee-for-service and mixed systems of payment: effects on the behaviour of primary care physicians. Cochrane Database Syst Rev 2000; (3): CD002215. doi: 10.1002/14651858.CD002215

6. O'Reilly J, Busse R, Hakkinen U, Or Z, Street A, Wiley M. Paying for hospital care: the experience with implementing activitybased funding in five European countries. Health Econ Policy Law 2012; 7: 73-101. doi: 10.1017/S1744133111000314

7. Glickman SW, Schulman KA, Peterson ED, Hocker MB, Cairns CB. Evidence-based perspectives on pay for performance and quality of patient care and outcomes in emergency medicine. Ann Emerg Med 2008; 51: 622-31. doi: 10.1016/j. annemergmed.2008.01.010

8. Greene J. An examination of pay-for-performance in general practice in Australia. Health Serv Res 2013; 48: 1415-32.

9. Harzband P, Groopman J. How medical care is being corrupted. New York Times [serial on the Internet]. Nov 19, 2014. Available from: http://www.nytimes.com/2014/11/19/opinion/how-medicalcare-is-being-corrupted.html?_r=0

10. Ikegami N. Games policy makers and providers play: Introducing case-mix-based payment to hospital chronic care units in Japan. J Health Polit Policy Law 2009; 34: 361-80. doi: 10.1215/03616878-2009-003

11. Ikegami N. Universal Health Coverage for Inclusive and Sustainable Development Lessons from Japan [internet]. 2014; http://documents.worldbank.org/curated/en/2014/09/20278271/ universal-health-coverage-inclusive-sustainable-developmentlessons-japan 